Article

\title{
An Investigation on the Use by Academic Researchers of Knowledge from Scientific Social Networking Sites
}

\author{
Vincenzo Corvello $^{1, * \mathbb{D}}$, Maria Cristina Chimenti ${ }^{1}$, Carlo Giglio ${ }^{2} \mathbb{D}$ and Saverino Verteramo ${ }^{1}$ \\ 1 Energy and Management Engineering, Department of Mechanical, University of Calabria, 87036 Rende, \\ Italy; mariacristina.chimenti@gmail.com (M.C.C.); saverino.verteramo@unical.it (S.V.) \\ 2 Environmental and Material Engineering, Department of Civil, Energy, Mediterranean University of Reggio \\ Calabria, 89124 Reggio Calabria, Italy; carlo.giglio@unirc.it \\ * Correspondence: vincenzo.corvello@unical.it
}

Received: 29 October 2020; Accepted: 20 November 2020; Published: 22 November 2020

\begin{abstract}
Scientific social networking sites like ResearchGate or Academia.edu have become part of the work practice of academic researchers. These digital platforms have been designed precisely to encourage the exchange of knowledge between scholars and to help the expansion of collaborative networks among them. Even if studies on this topic have multiplied in recent years, there is a dearth of research on the actual impact of these platforms on scientific production. The goal of this study is to investigate the relationship between the attitude of researchers towards scientific social networks and the use of knowledge in their scientific work. Data from users of the scientific social networking site ResearchGate were collected. A total of 143 valid responses were received and structural equation modeling was applied for data analysis. Findings of this study confirmed that researchers use knowledge obtained from scientific social networking sites both incorporating it within their research products and to acquire new competences. In particular approaching the platform as a scientific community with a shared language and a shared vision was found to have a positive impact on knowledge use. To the best knowledge of the authors this is the first study investigating the actual use of knowledge from scientific social networking sites by academic researchers. Results help us to understand the impact of these platforms on the work practice of a strategic sector like scientific research.
\end{abstract}

Keywords: scientific social network; knowledge network; academic research; knowledge transfer; collaboration

\section{Introduction}

Scientific research plays a key role in economic and social growth. Economic progress largely depends on innovation, the vast majority of which requires some degree of scientific research [1]. Scientific research projects generally involve knowledge-intensive teams that necessitate participants to share knowledge while working together. Knowledge sharing among researchers is supported by higher institutions because it promotes critical thinking [2] and learning [3]. Traditionally, researchers find new opportunities to collaborate among colleagues in their institutions, through academic conferences, exchanging academic visits [4]. As a result of the diffusion of information and communication digital technologies, academic collaboration is undergoing an impressive transformation from physical to web interaction [5]. Information communication technology (ICT) facilitates learning and provides faster and more efficient channels for knowledge sharing [6].

With the growth of Web 2.0, social networking websites emerged and soon turned out to be the web users' favorite places to generate and share information and to communicate with each 
other $[7,8]$. Social networking influence is increasingly pervasive and spreads in contexts that were initially unthinkable as a support tool for educational activities [9].

In this context it is important to study which factors influence the user willingness toward knowledge sharing in social networks. Zhao et al. [10] underline the role of perceived value (depending on social value, entertainment value, emotion value and information value) and trust.

For this reason, researchers engage with social networking platforms for collaboration and knowledge sharing [6,11]. Scientific Social Network Sites (SSNS) are web platforms specifically created for researchers and aimed at the communication, dissemination and exchange of science-related information between the interested members [12]. These platforms allow academics to follow how the documents they share are used by the online community, obtaining rapid feedback on the impact of their results in the web environment [8]. Several SSNS are available for researchers, including Academia.edu, Mendeley and ResearchGate. ResearchGate has more than 15 million members [13], while over 114 million academics have signed up to Academia.edu [14]. Mendeley, as a primary reference manager which included social networking features, also exceeds 6 million users [15].

Literature on SSNS has grown in recent years. Research has focused on a wide range of topics like the demographics of SSNS [16-18], intention to adopt SSNS [17,19], motivations for using SSNS [20,21], impact on social capital [6]. Academic social networks have been found useful in expanding a researcher's network [17] as well as enhancing a researcher's knowledge sharing behavior [6].

In spite of the fact that in the last few years research contributions regarding SSNS have increased, their impact on researchers' output has not been investigated [22]. Collaboration is essential for scientific quality and productivity, because it guarantees access to novel and reliable knowledge [23,24]. The characteristics of an individual and the work environment are endogenously related to both collaboration and scientific productivity $[23,25,26]$. SSNS can quickly connect and support researchers [6]. Therefore, it is expected that members of SSNS experience improvements in their work and scientific results. It is necessary to investigate the relation between the use of SSNS and the output of researchers. It is important, in particular, to understand under what conditions SSNS have a positive impact on the acquisition of new knowledge, that is expected to lead to an improved scientific output. If we consider SSNS as a knowledge sharing platform, perceived usefulness and satisfaction degree have a significant influence on continued use intention [27].

The existing literature on productivity in scientific research underlines that scientific knowledge sharing in academia is influenced by a researcher's perception of the characteristics of the scientific community [28,29] and of the possible personal advantages collaboration offers [30,31]. Some researchers participate in SSNS and become members of the community, others adopt a utilitarian approach, accessing the website to find solution to specific problems [32-34].

This study investigates the circumstances under which the use of SSNS impacts on a researcher's output in terms of knowledge acquisition and use. In particular, use of knowledge from SSNS in a researcher's scientific output and scientific competence acquisition are the dependent variables. Based on the review of the literature the impact of personal beliefs on these two variables has been investigated. Four personal beliefs have been considered: shared vision, shared language, competence and reciprocity. The first two reflect a collaborative approach of the researcher with the community while the other two are associated with a utilitarian approach.

The results of this study are useful for SSNS providers in order to improve their platforms features as well as for researchers, in order to better understand knowledge acquisition and utilization processes in a SSNS context. Finally, the results may be relevant for academics and policymakers interested in the evaluation of scientific research and in the improvement of its results from both a quantitative and qualitative point of view. 


\section{Literature Review}

\subsection{Scientific Social Networking Sites, Knowledge Sharing and Knowledge Use}

In recent years, SSNS use in academia is becoming more commonplace [35]. Several studies have focused on the motivations for using SSNS [19].

Gaining visibility and reputation is one of the most frequently cited reason [36]. Researchers use SSNS to gain personal reputation [37], visibility of their work and publications [38,39] or, less often, of their institution $[19,35]$. According to this vision, researchers use SSNS in an active way (they do not prevalently use the system passively to consult documents) and with the purpose of obtaining an advantage for themselves or for their institution.

Another, equally widespread point of view, underlines the use of SSNS as sources of scientific knowledge [21,40-42]. Researchers passively consult documents uploaded by their colleagues [19]—sometimes, unconsciously infringing the copyright [43]—or actively seek the knowledge they need through the use of features like "question and answers" [40]. This attitude is often found in junior researchers or graduate students but it is also common among more experienced users [44]. Scholars consider SSNS as a means to retrieve knowledge they are not able to find in their proximal network of contacts [18].

Several studies concerned with knowledge sharing and acquisition on SSNS, focus on specific features of the platforms, like question and answers [40,45], relational capital and needs-based mechanisms for self-disclosure behavior [39] or networking (metrics and interactions, platform demographics and social structure, user perspectives and Open Access) [46].

Two approaches can be identified in the analyzed literature on knowledge sharing on SSNS both in studies focusing on specific features and in those considering the platforms as a whole. According to the first approach, researchers see SSNS as readily available repositories or sources of knowledge. According to the second approach SSNS are seen as scientific communities. While for most researchers one of the two attitudes towards SSNS prevails, many other adopt both the points of view in approaching these platforms $[18,19,35]$.

The first approach considers the SSNS as a tool or a service: the researcher uses the platform as a source of knowledge to solve specific problems. For example, focusing on knowledge acquisition and sharing, Waheed and colleagues underline that the perceived quality of knowledge obtained from academic social media is a critical variable in determining a researcher's satisfaction with the platform. In turn, satisfaction impacts on perceived learning and researcher's loyal behavior [42]. Williams [47] has found that accessing knowledge is the main reason for using Academia.edu in order to increase impact and reach of their research as well as to help them building scholarly brands and identities. Deng and colleagues analyzed the characteristics of popular question and answers on ResearchGate $[40,45]$. They found that researchers prefer short answers with positive action-oriented statements, revealing a pragmatic approach oriented at finding solutions to specific problems. Lee and colleagues conducted a survey among ResearchGate users on the motivations for using the platform by considering factors from personal, professional, social and external contexts [48]. They found that accessibility of knowledge was the main reason for using the system. Moreover, Yu et al. found that what is peculiar of ResearchGate is that usage activities are transformed into individual researcher performance measurements [49].

The second approach considers SSNS as communities. Researchers value membership in these communities. According to this point of view, researchers habitually access the website and interact with its users [50-54]. Nández and Borrego [38] suggest that getting in touch with other researchers, disseminating their research results and following other researchers' activities is the main reason for participating in SSNS, without need for an immediate objective. Similarly, the study conducted by Corvello et al. [11] suggests that academics mostly use SSNS as a means to communicate and share their results and their knowledge. Yan and colleagues analyzed the use of the "follow" function in ResearchGate, finding that, while some researchers "follow" other users in order to obtain specific 
pieces of information, over fifty percent of users become followers of colleagues without an immediate goal but aware that a network on the SSNS can be a valuable source of knowledge in the medium-long term [53].

While the above cited studies address the topic of knowledge sharing and acquisition on SSNS, there is a dearth of research on the actual impact of SSNS on the scientific production of researchers [52]. Researchers use SSNS to seek for scientific knowledge using the platforms as a repository or interacting with the underlying community but it is not clear when and how much they use the knowledge they obtain in their work.

\subsection{Research Model}

To fill the research gap highlighted above, this study aims to investigate the relationship between the attitude of a researcher towards SSNS on the one hand and the actual use of the knowledge obtained, on the other. In particular, as discussed in the previous section, the attitude of the researcher can be twofold: (1) he considers the SSNS as a repository to be used to find specific pieces of information and knowledge; (2) he considers SSNS as communities in which to build new knowledge through more or less intense interaction practices. In the first case we define the attitude of the researcher "transactional attitude." In the second case we use the expression "membership attitude." As discussed above the two "attitudes" intertwine and the same researcher can identify with both views at the same time.

The research model shown in Figure 1 represents the hypothesized and investigated relationships in this research. The individual variables and assumptions are discussed in detail below in this paragraph.

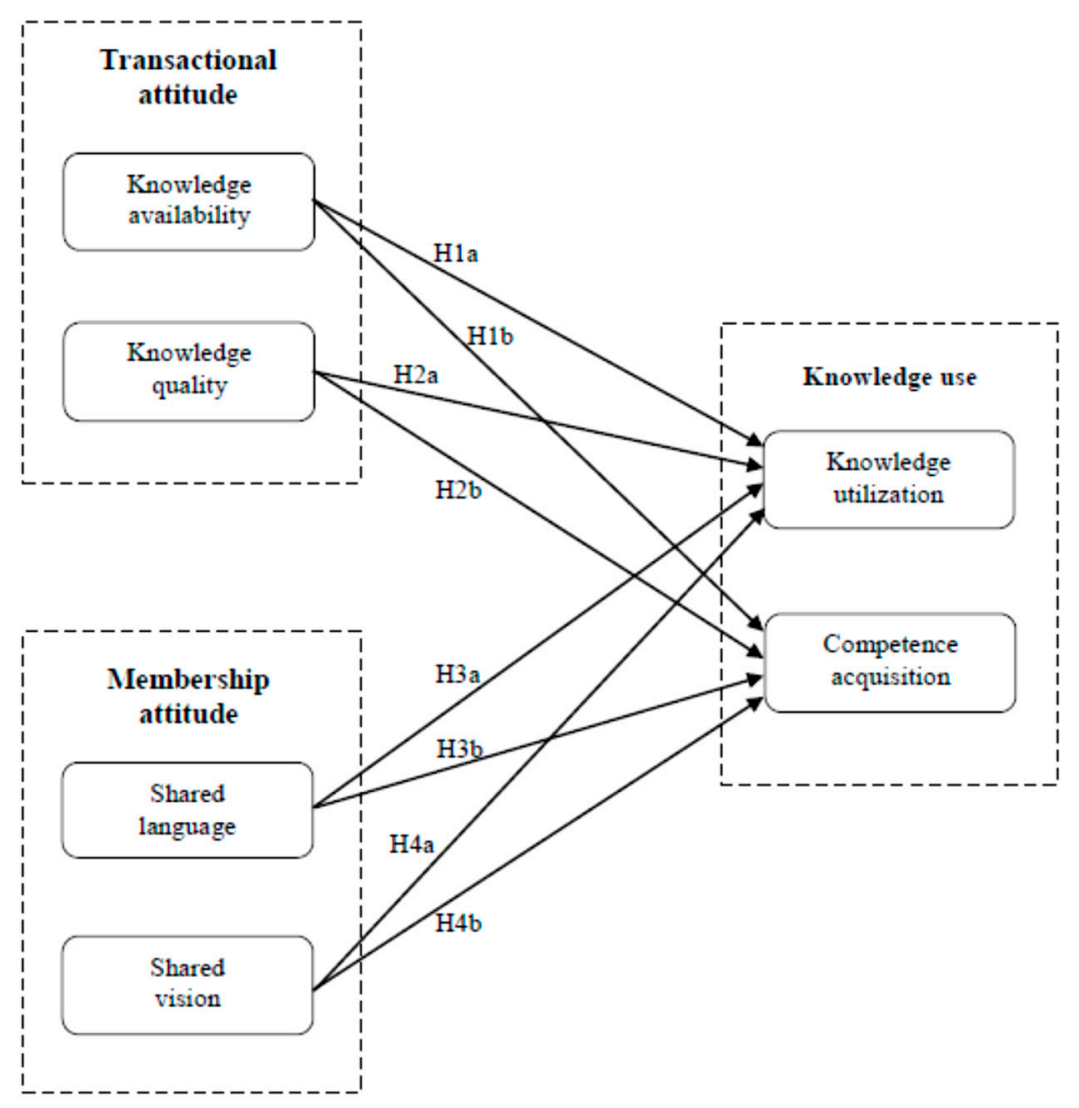

Figure 1. Research model.

Knowledge use. The goal of this paper is to get a better understanding of the conditions under which researchers actually benefit from participation in SSNS. While the topic has been neglected by the literature on SSNS, it has been addressed by scholars in other, related fields like virtual communities [39,55], online social question and answers communities [56], online review systems [57]. 
Knowledge retrieved online can be used to solve specific problems or as a basis to develop new competences [58]. When considering scientific research, the first situation coincides with the incorporation by a researcher of the knowledge obtained online in his scientific products. For this specific case we use the expression "knowledge utilization" [55]. The second situation consists in the acquisition of new competences in conducting scientific research [46,54]. The attitude of researchers towards SSNS is expected to influence knowledge use, both considered as knowledge utilization and competence acquisition (see Section 2.1).

Transactional attitude. SSNS provide researchers with powerful means to find solutions to specific difficulties met during their work [40,42,47]. As a repository a SSNS provide easy access to publications and other documents [48]. Through the questions and answers function they offer the possibility to ask for advice to solve specific problems [40].

Researchers will use SSNS as far as they expect that their questions (explicit or implicit) will be answered. If researchers perceive that they frequently find solutions to their problems, they will systematically use knowledge obtained from SSNS in their work and will perceive that SSNS contributed to developing their scientific competences. We define "knowledge availability" the perception of the researcher that he can easily find on SSNS a solution to difficulties met during his work. The following hypotheses can be formulated:

Hypothesis 1a (H1a). The level of knowledge availability on SSNS has a positive impact on knowledge utilization.

Hypothesis $\mathbf{1 b} \mathbf{( H 1 b ) . ~ T h e ~ l e v e l ~ o f ~ k n o w l e d g e ~ a v a i l a b i l i t y ~ o n ~ S S N S ~ h a s ~ a ~ p o s i t i v e ~ i m p a c t ~ o n ~}$ competence acquisition.

As for other online resources, it is expected that the use of knowledge obtained from SSNS, both considered as knowledge utilization and as competence acquisition, is influenced by the researcher's perception of its quality level [55]. We define "knowledge quality" the perception of the researcher of the degree to which the source of knowledge on the SSNS (i.e., the researcher who shared the document or answered a question) can be relied upon. The following hypotheses can be formulated:

Hypothesis 2a (H2a). The level of perceived quality of knowledge obtained on SSNS has a positive impact on knowledge utilization.

Hypothesis $\mathbf{2 b} \mathbf{b} \mathbf{H} \mathbf{2} \mathbf{b})$. The level of perceived quality of knowledge obtained on SSNS has a positive impact on competence acquisition.

Membership attitude. SSNS are designed to support continued interaction among their members. Functions like "follow" a member on ResearchGate [53] or different forms of feedback and alerts, allow the formation of virtual links [46], increase visibility of researchers and institutions [59] and generate loyalty towards the community [42]. Researchers participate without an immediate, specific objective: they participate because they value membership in the community. Members of virtual communities share a common language (i.e., codes, vocabulary, references) which enhances a common understanding of the topics they discuss. In turn, a common understanding has been found to result in an increase in knowledge sharing [60]. Similarly, shared language is expected to increase knowledge use by SSNS users. Thus:

Hypothesis 3a (H3a). Shared language has a positive impact on knowledge utilization.

Hypothesis $\mathbf{3 b} \mathbf{( H 3 b ) . ~ S h a r e d ~ l a n g u a g e ~ h a s ~ a ~ p o s i t i v e ~ i m p a c t ~ o n ~ c o m p e t e n c e ~ a c q u i s i t i o n . ~}$ 
Members of a community often share values and goals. Shared vision is the extent to which individuals share goals, concerns and purpose [61] and it has been found to facilitate knowledge sharing in virtual communities [62]. Thus, the following hypotheses can be formulated:

Hypothesis 4a (H4a). Shared vision has a positive impact on knowledge utilization.

Hypothesis $\mathbf{4 b} \mathbf{b} \mathbf{H} \mathbf{4 b})$. Shared vision has a positive impact on competence acquisition.

\section{Research Methodology}

\subsection{Questionnaire Design}

This research study has been conducted by using a questionnaire composed of two sections: the first one includes items associated with the constructs in the theoretical model; the second one consists of items relates to data on socio-demographic aspects, academic career and scientific social networks. Before such sections, the questionnaire provides a description of SSNs, study purpose and impacts.

The process followed to define the measurement items includes a review of literature followed by an elicitation study [63] and an item validation process, since there is no standard questionnaire for the proposed model. This way, scholars may exploit a questionnaire geared to the analysis of a specific behavior and population of interest.

The elicitation phase was conducted by engaging twenty people in a focus group, representative of the study population in terms of ages, academic roles and other variables in Table 1. Such a formative research process was realized by phone. Interviewees were asked to respond a set of questions aimed at making explicit new measurement items for belief constructs.

Table 1. Characteristics of the sample.

\begin{tabular}{ccc}
\hline & Sample $(\boldsymbol{N}=\mathbf{1 4 3}) \mathbf{( \% )}$ & \\
\hline Gender & Male & $55.49 \%$ \\
Age & Female & $44.51 \%$ \\
& $25-34$ & $19.75 \%$ \\
& $35-44$ & $32.10 \%$ \\
& $45-55$ & $39.51 \%$ \\
& $55+$ & $8.64 \%$ \\
Academic level & Full professor & $6.17 \%$ \\
& Associate professor & $23.46 \%$ \\
& Assistant professor & $37.04 \%$ \\
& Adjunct professor & $2.47 \%$ \\
& Research fellow & $1.23 \%$ \\
& Post-doc & $14.81 \%$ \\
& Ph.D. student & $4.94 \%$ \\
& Technician & $1.23 \%$ \\
& Blank & $8.64 \%$ \\
\hline
\end{tabular}

The output of this elicitation process was reviewed by other sixteen people, proving to be reliable and clear. The final questionnaire utilizes a 5-point Likert-type scale $(1=$ strongly disagree/bad, 5 = strongly agree/good [64]. The final items can be found in Table 2.

This work readapted existing validated items in the extant literature to assess the predictor constructs utilized in our model $[40,42,46-48,53,55,59,60]$. Constructs were measured by means of multi-item scales $[65,66]$, while the "response set" was handled by reverse-scaling three measurement items and deleting incoherently completed questionnaires. 
Table 2. Measurement Scales.

\begin{tabular}{|c|c|c|}
\hline Factor/Item & $\begin{array}{l}\text { Corrected Item-to-Total } \\
\text { Correlation }\end{array}$ & $\begin{array}{c}\text { Cronbach's } \\
\text { Alpha-if-Item-Deleted }\end{array}$ \\
\hline \multicolumn{3}{|l|}{$\mathrm{KA}(\alpha=0.712)$} \\
\hline $\begin{array}{l}\text { KA 1-I expect the other researchers will share their } \\
\text { knowledge }\end{array}$ & 0.480 & 0.686 \\
\hline KA 2-Other members answer my questions & 0.652 & 0.487 \\
\hline $\begin{array}{l}\text { KA 3-I know other members would help me, if needed } \\
\text { SV }(\alpha=0.882)\end{array}$ & 0.478 & 0.693 \\
\hline $\begin{array}{l}\text { SV 1-Members I interact with share the vision to help } \\
\text { others to solve their professional problems }\end{array}$ & 0.720 & 0.877 \\
\hline $\begin{array}{l}\text { SV 2-Members I interact with share the same objective to } \\
\text { learn from each other }\end{array}$ & 0.800 & 0.806 \\
\hline $\begin{array}{l}\text { SV 3-Members I interact with share the same value that } \\
\text { helping others to is pleasant } \\
\mathrm{KQ}(\alpha=0.940)\end{array}$ & 0.794 & 0.812 \\
\hline KQ 1-Members I interact with do a good job in their areas & 0.843 & 0.937 \\
\hline KQ 2-Members I interact with are experts in their areas & 0.891 & 0.900 \\
\hline $\begin{array}{l}\text { KQ 3-Members I interact with are qualified in their areas } \\
\text { SL }(\alpha=0.891)\end{array}$ & 0.893 & 0.899 \\
\hline $\begin{array}{l}\text { SL } 1 \text {-Sharing my competences through RG is compatible } \\
\text { with my personal values }\end{array}$ & 0.829 & 0.807 \\
\hline $\begin{array}{l}\text { SL } 2 \text {-Sharing my competences through RG complies with } \\
\text { my current needs }\end{array}$ & 0.823 & 0.816 \\
\hline $\begin{array}{l}\text { SL } 3 \text { - Sharing my competences through RG complies with } \\
\text { my working style } \\
\text { CA }(\alpha=0.925)\end{array}$ & 0.714 & 0.906 \\
\hline $\begin{array}{l}\text { CA } 1 \text {-Sharing my competences through RG will improve } \\
\text { my problem solving skills }\end{array}$ & 0.824 & 0.909 \\
\hline $\begin{array}{l}\text { CA } 2 \text {-Sharing my competences through RG will help me } \\
\text { to respond to the changes affecting my area }\end{array}$ & 0.842 & 0.895 \\
\hline $\begin{array}{l}\text { CA 3-Sharing my competences through RG will make me } \\
\text { more effective and performing at work } \\
\text { KU }(\alpha=0.919)\end{array}$ & 0.874 & 0.868 \\
\hline $\begin{array}{l}\text { KU } 1 \text {-I often use knowledge from RG to solve my } \\
\text { professional problems }\end{array}$ & 0.825 & 0.893 \\
\hline $\begin{array}{l}\text { KU 2-I frequently use knowledge from RG to improve } \\
\text { my competences }\end{array}$ & 0.881 & 0.846 \\
\hline $\begin{array}{l}\text { KU 3-I regularly use knowledge from RG to manage } \\
\text { changes in my work }\end{array}$ & 0.803 & 0.910 \\
\hline
\end{tabular}

$\alpha=$ Cronbach's alpha; KA = Knowledge availability; SV = Shared Values; KQ = Knowledge Quality; SL = Shared Language; $\mathrm{CA}=$ Competence Acquisition; $\mathrm{KU}=$ Knowledge Utilization.

\subsection{Data Collection}

The formative research process was realized in November 2019 by involving a quota sample of twenty academicians. The data were collected during the period from November 2019 to January 2020 through a paper-based questionnaire administered to academicians at the University of Calabria (Italy). Since both the questionnaire design and data collection phases, a mixed approach of procedural and statistical measures has been implemented in order to avoid the common method bias (CMB) [67]. As for procedures, all measures have been clearly separated according to spatial, temporal and psychological criteria, whilst the overall design process took into account also the structure and features of the survey as well as the study context [67]. Finally, statistical analyses-i.e., Harman's single-factor test-have been utilized [67].

As a result, 143 valid responses were obtained out of 159 complete responses (valid response rate of $89.94 \%$ ). $59.26 \%$ of valid responses are male and $40.74 \%$ are female. The respondents' age groups and academic positions are shown in Table 1.

About $66.67 \%$ of the respondents are professors (at either the assistant, associate or full level), while $33.32 \%$ are research fellows, adjunct professors, doctoral students et similia. About $75.31 \%$ work in medical-scientific areas, $11.11 \%$ in the socio-economic one and $2.47 \%$ in the human sciences $(11.11 \%$ 
did not specify). $19.75 \%$ of respondents are $25-34$ years old, $32.10 \%$ are $35-44 \%, 39.51 \%$-the relative majority-are $45-55$ and $8.64 \%$ are $55+$.

\subsection{Data Analysis}

The first methodological step consisted in the exploratory factor analysis (EFA) with Promax/oblique rotation, Bartlett's and Kaiser-Meyer-Olkin's (KMO) tests-through which the proper design of survey items per each factor was verified.

In the second step, the SEM analysis was applied by including both the confirmatory factor analysis (CFA) and path analysis (PA). The latter is utilized to test complicated models with a number of endogenous/concatenate variables [68], whilst CFA analyzes grouped items against constructs in order to assess whether collected data fit the model. SEM tests multiple relationships between latent constructs at the same time, together with mediating/moderating effects [69-71].

\section{Results}

\subsection{Data Screening and the Measurement Model}

First, data were checked in order to verify the general linear assumption. Then, EFA was performed by using Maximum Likelihood (ML), Horn's procedure and Promax rotation [72-74]. Construct unidimensionality, correlation significance and suitability for factor analysis were verified. The reliability of constructs was tested through Cronbach's alpha and item-to-total correlation [75], while CFA was also used to test construct validity [76] and the model hypotheses were checked by means of PA and SEM with robust ML/Satorra-Bentler scaled chi-squared, since the multivariate normality assumption was rejected $[77,78]$.

\subsubsection{Reliability Analysis and Exploratory Factor Analysis (EFA)}

The internal reliability of items was verified through Cronbach's alpha values, Alpha-if-Item-Deleted (AID) and Item-to-Total Correlation (ITC) shown in Table 2 [66]. Alpha values are far above 0.7 , proving strong reliability of data [79]. The scale wan not modified after the reliability check, indeed.

Bartlett's sphericity test $(2071.471$, significaneice $=0.000, \mathrm{df}=153)$ proves that variables correlation is significant, whilst KMO (0.875) ensures the feasibility of factor analysis [80].

Harman's single-factor test suggests that the total variance explained is $43.663 \%$ : CMB has been avoided.

During the Exploratory Factor Analysis (EFA), the Horn's extraction method was run by choosing 6 extracted factors [81-83], since other extraction procedures (e.g., Principal Component Analysis [PCA]) proved to cause a higher information loss. Both convergent and discriminant validity are satisfied each factor has a biunivocal association with high-load items.

Oblique rotation further suggested that measured variables for each construct have no high loadings on other latent variables: items were grouped with corresponding loadings close to the 0.5 threshold. Also, running different rotations did not improve the results. Moreover, Kaiser's Rule and Scree Plot were satisfied.

\subsubsection{Confirmatory Factor Analysis (CFA)}

Confirmatory Factor Analysis (CFA) detects those measured variables grouped and associated with underlying constructs and checks whether data fit the model.

Unlike EFA, CFA has the potential to detect the factor structure of constructs and purify the model from non-valid items, depending on unidimensionality, reliability and validity criteria [84].

The fit indices satisfy the main goodness-of-fit thresholds $\left(\chi^{2}=206.590 ; \mathrm{df}=120 ; p\right.$-value $=0.000$; $\chi^{2} / \mathrm{df}=1.722$; Root Mean Squared Error of Approximation (RMSEA) $=0.0670 ; p$-value Test of Close Fit $=0.0538$; Standardized Root Mean Square Residual $($ StdRMR $)=0.0616$; Normed Fit Index 
$(\mathrm{NFI})=0.954$; Confirmatory Fit Index $(\mathrm{CFI})=0.980$; Tucker-Lewis Index $(\mathrm{TLI}) \triangleq$ Non-Normed Fit Index $(\mathrm{NNFI})=0.974)$ [73]. First, as for absolute fit indices, the $\chi^{2} /$ degrees of freedom is excellent. The RMSEA — which, as is common knowledge, typically performs bad when the sample size $(\mathrm{N})$ is low-in this case provides excellent fit statistics, despite its $p$-value is not good. However, Std RMR-which is the best index to detect wrong models-is around the threshold of excellence. Incremental fit indices such as NFI, CFI, NNFI are excellent, too. Finally, CFA results show an overall excellent fit.

The goodness-of-fit is further confirmed by the residuals: they do not form any blocks and |Std Residuals $\mid<3$. Moreover, the Q-plot of Std residuals I aligned on the bisector.

Table 3 reports CFA results for each item and construct: factor loadings are higher than the 0.40 threshold, $\mid t$-values $\mid>3.096$ ( $p$-value $<0.001$ ), thus, confirming convergent validity [72] and unidimensionality.

Table 3. Confirmatory Factor Analysis Measurement Scales.

\begin{tabular}{|c|c|c|}
\hline Factor/Item & Completely Std Loading Value & $t$-Value \\
\hline \multicolumn{3}{|c|}{$\mathrm{KA}(\alpha=0.712 ; \mathrm{CR}=0.733 ; \mathrm{AVE}=0.482)$} \\
\hline $\mathrm{KA} 1^{\mathrm{a}}$ & 0.572 & - \\
\hline KA 2 & 0.814 & 5.685 \\
\hline KA 3 & 0.676 & 5.559 \\
\hline \multicolumn{3}{|c|}{$\mathrm{SV}(\alpha=0.882 ; \mathrm{CR}=0.885 ; \mathrm{AVE}=0.719)$} \\
\hline SV $1^{\mathrm{a}}$ & 0.785 & - \\
\hline SV 2 & 0.889 & 11.238 \\
\hline SV 3 & 0.867 & 11.027 \\
\hline \multicolumn{3}{|c|}{$\mathrm{KQ}(\alpha=0.940 ; \mathrm{CR}=0.941 ; \mathrm{AVE}=0.842)$} \\
\hline $\mathrm{KQ} 1^{\mathrm{a}}$ & 0.876 & - \\
\hline KQ 2 & 0.934 & 16.819 \\
\hline KQ 3 & 0.941 & 17.027 \\
\hline \multicolumn{3}{|c|}{$\mathrm{SL}(\alpha=0.891 ; \mathrm{CR}=0.898 ; \mathrm{AVE}=0.746)$} \\
\hline SL $1^{a}$ & 0.907 & - \\
\hline SL 2 & 0.899 & 15.175 \\
\hline SL 3 & 0.780 & 11.869 \\
\hline \multicolumn{3}{|c|}{$\mathrm{CA}(\alpha=0.925 ; \mathrm{CR}=0.925 ; \mathrm{AVE}=0.804)$} \\
\hline $\mathrm{CA} 1^{\mathrm{a}}$ & 0.890 & - \\
\hline CA 2 & 0.871 & 14.834 \\
\hline CA 3 & 0.929 & 17.008 \\
\hline \multicolumn{3}{|c|}{$\mathrm{KU}(\alpha=0.919 ; \mathrm{CR}=0.922 ; \mathrm{AVE}=0.797)$} \\
\hline KU $1^{a}$ & 0.883 & - \\
\hline KU 2 & 0.935 & 16.388 \\
\hline KU 3 & 0.862 & 14.140 \\
\hline
\end{tabular}

$\alpha=$ Cronbach's alpha; $\mathrm{CR}=$ composite reliability; $\mathrm{AVE}=$ average variance extracted. ${ }^{\text {a }}$ Item with corresponding lambda imposed equal to $1 . \mathrm{KA}=$ Knowledge availability; $\mathrm{SV}=$ Shared Values; $\mathrm{KQ}=$ Knowledge Quality; $\mathrm{SL}=$ Shared Language; $\mathrm{CA}=$ Competence Acquisition; $\mathrm{KU}=$ Knowledge Utilization .

CR is never lower than 0.70 for all the scales, whilst AVE is below threshold (0.50) only for KA but very close to it-i.e., 0.482: the latter result may be generated by the small sample size [85]. Such a scale may require a minor revision in further studies.

The discriminant check is run by making a comparison of the AVEs of two latent factors, on the one hand and the coefficient of determination-i.e., square of their correlation coefficient-, on the other hand. If the former is greater than the latter, the discriminant validity between the factors is proven $[84,86]$. The results of this research work satisfy this condition for all couples of factors [87], as reported in Table 4. 
Table 4. Construct Summary Statistics: Measure Correlations, Reliability Coefficients and Square Root of AVE.

\begin{tabular}{ccccccccc}
\hline & KA & SV & KQ & SL & CA & KU & CR & AVE \\
\hline KA & 1 & & & & & & 0.733 & 0.482 \\
SV & 0.517 & 1 & & & & & 0.885 & 0.719 \\
KQ & 0.346 & 0.458 & 1 & & & & 0.941 & 0.842 \\
SL & 0.347 & 0.443 & 0.539 & 1 & & & 0.898 & 0.746 \\
CA & 0.411 & 0.521 & 0.502 & 0.738 & 1 & & 0.925 & 0.804 \\
KU & 0.343 & 0.442 & 0.425 & 0.579 & 0.805 & 1 & 0.922 & 0.797 \\
Mean & 3.636 & 3.268 & 3.604 & 3.483 & 3.075 & 2.671 & & \\
SD & 0.994 & 0.783 & 0.931 & 0.893 & 0.964 & 1.064 & & \\
\hline
\end{tabular}

KA = Knowledge availability; SV = Shared Values; KQ = Knowledge Quality; SL = Shared Language; $\mathrm{CA}$ = Competence Acquisition; $\mathrm{KU}=$ Knowledge Utilization; $\mathrm{SD}=$ standard deviation; $\mathrm{CR}=$ composite reliability; and AVE = average variance extracted.

\subsection{Structural Model, Path Analysis, Hypotheses Testing and Full SEM Analysis}

PA led to realize the structural model in Figure 1 that was tested through the full SEM analysis. Fit indices were excellent $\left(\chi^{2}=254.159 ; \mathrm{df}=121 ; p\right.$-value $=0.00 ; \chi^{2} / \mathrm{df}=2.101 ; \mathrm{RMSEA}=0.0774 ; p$-value Test of Close Fit $=0.00346 ;$ StdRMR $=0.0807 ; \mathrm{NFI}=0.943 ; \mathrm{CFI}=0.969 ; \mathrm{TLI} \triangleq \mathrm{NNFI}=0.961$ ) [73]. The $\chi^{2} / \mathrm{df}$ is excellent. As for RMSEA, despite a low-size $(\mathrm{N})$ sample generally making it a bad-performing index-providing generally conservative results-, this index proves the goodness of the model with acceptable fit statistics. Also, Std RMR (the best to detect wrong models) is around the threshold of acceptability. Coherently, also incremental fit indices can be accepted (e.g., NFI) or are sometimes excellent (e.g., NNFI) and the most reliable and commonly used one that is CFI. Hence, the proposed model proves to have an overall excellent goodness-of-fit.

No blocks of residuals are detected, almost all $\mid$ Std Residuals $\mid<3$, their $\mid t$-values $\mid>3.096$ ( $p$-value $<0.001)$ and the Q-plot matches the bisector.

The test of the hypothesized relationships is reported in Table 5: results support some hypotheses. In detail, some exogenous constructs impact on the two endogenous variables, namely $\mathrm{CA}$ and $\mathrm{KU}$, as shown by the estimates of standardized coefficients.

Table 5. Hypotheses Testing.

\begin{tabular}{cc}
\cline { 2 - 2 } Hypothesized Paths & Coefficients \\
$\mathrm{KA} \rightarrow \mathrm{CA}$ & 0.077 \\
$\mathrm{SV} \rightarrow \mathrm{CA}$ & $0.170^{* *}$ \\
$\mathrm{KQ} \rightarrow \mathrm{CA}$ & 0.099 \\
$\mathrm{SL} \rightarrow \mathrm{CA}$ & $0.545^{*}$ \\
$\mathrm{KA} \rightarrow \mathrm{KU}$ & 0.020 \\
$\mathrm{SV} \rightarrow \mathrm{KU}$ & $0.188^{* *}$ \\
$\mathrm{KQ} \rightarrow \mathrm{KU}$ & 0.107 \\
$\mathrm{SL} \rightarrow \mathrm{KU}$ & $0.142 *$ \\
$* p<0.001 ; * *=p<0.05 ; \mathrm{KA}=\mathrm{Knowledge}$ availability; SV = Shared Values; KQ $=$ Knowledge Quality; SL $=$ Shared
\end{tabular}

\section{Discussion and Conclusions}

\subsection{Main Findings}

SSNS are by now widespread in the academic world and have become part of the work of researchers [35]. They have been studied as means for gaining visibility and reputation [36] but also as milieus for knowledge sharing [40-42,88]. 
To our knowledge, however, this is the first study focusing on the actual use of knowledge obtained from SSNs by researchers. Investigating if knowledge from SSNS is useful for researchers in their work is important to understand the actual impact of these platforms on scientific research.

Taking ResearchGate as a case study, our work investigated, in particular, the impact of the researcher's attitude towards SSNS on knowledge use [18,19,35]. Two possible attitudes have been considered: (1) researchers see SSNS as tools giving access to readily available knowledge [2,40-42] researchers see SSNS as scientific communities [38,53].

Our findings show that researchers actually use the knowledge retrieved or generated on SSNS in their work, thus supporting the idea that these platforms have an impact on scientific practices and productivity [52]. Respondents in our study confirmed that they incorporate pieces of knowledge obtained from ResearchGate into their scientific products (i.e., knowledge utilization) and that they improved their scientific competences through interaction with the members of the social network (i.e., competence acquisition).

The most relevant results of this study, however, relate to the impact of the researcher's attitude on the use of knowledge. While our hypotheses on the positive impact of a "membership attitude" on knowledge use were supported, the relations between "transactional attitude" and "knowledge utilization" or "competence acquisition" were not found to be statistically relevant.

In our hypotheses researchers were assumed to access SSNS in search for solutions to specific problems. What would induce a researcher to use the knowledge obtained from a SSNS was the availability of knowledge answering his questions on the one hand and the perceived quality of this knowledge on the other. These hypotheses were not supported, proving that in the analyzed case the availability of knowledge and the perception of this knowledge as generated by a reliable source, are not sufficient to determine either its incorporation in scientific products or learning of new competences. This is in contrast with the findings of other studies in related fields, like virtual communities of professionals [55] or entrepreneurs [89]. This might be due to the specific nature of the community considered: scientific researchers. The level of complexity and specificity of the knowledge involved in scientific research make it difficult for researchers to fully rely on unknown sources. This concept deserves further investigation.

On the contrary, our results show a positive link between the two variables associated with the "membership attitude," shared language and shared vision and the use of knowledge, both in terms of inclusion in scientific products and as competence learning. Researchers use knowledge obtained from (or generated with) colleagues with a similar language because it is easily understood and easily integrated with their own knowledge [59]. Even stronger is the impact of a "shared vision": feeling part of the same community, in terms of values and objectives, is particularly important for scientists in order to consider the acquired knowledge reliable and compatible with their way of seeing the topics covered $[61,62,90]$. Consequently, considering the SSNS as a community and perceiving a commonality of objectives and values is a necessary prerequisite for the knowledge created on the platforms to have an impact on the products and scientific practices of researchers.

\subsection{Implications for Practice}

Our findings confirm the role that SSNS play in the contemporary practices of researchers and their impact on scientific production. Several implications for practice arise from this study for different categories of stakeholders. Our investigation suggests that SSNS have a greater impact when the researcher perceives to be part of the community. People interested in developing and sustaining knowledge sharing through SSNS may develop mechanisms to motivate members to participate in the community. For example, research managers can design reward systems to incentive participation.

The same researchers should consider that continuative participation in SSNS is expected to have a greater impact than occasional use. Developing regular work practices involving the use of SSNS might improve their productivity. 
Developers of SSNS, on the other hand, should continue to invest in networking functions, thus making stronger the aspect of the system with the greater impact on scientific output. While functionalities offering researchers visibility have short term results on the popularity of SSNS [36], systems improving their productivity might prove more attractive on the long run.

\subsection{Limitations and Future Research Directions}

There were several limitations to our study. First it considers only one specific SSNS, ResearchGate and only researcher belonging to one institution, University of Calabria. Even if ResearchGate is currently the most popular SSNS and University of Calabria includes researchers with diverse scientific interests and background, these characteristics of the sample limit the generalizability of results. Future research should test the investigated hypotheses in a wider context.

Secondly, two of the hypothesized relations were found to be not statistically significant. Even if this is still a result, highlighting how causal links verified in other contexts $[55,62]$ do not necessarily apply to SSNS, the reasons for this difference need further investigation.

The study only considered self-reported evaluations of the impact of SSNS on scientific practices and productivity. This aspect could be further elaborated through quantitative studies considering objective measure of productivity on the one hand and through qualitative studies investigating the modifications in work practices of researchers on the other. Perception surveys might be used in future studies to increase their effectiveness.

Finally, the study investigated only two dimensions of the "membership attitude." Further dimensions are expected to have an impact on knowledge use and should be considered in future studies.

Author Contributions: Conceptualization, V.C.; methodology, C.G.; formal analysis, C.G.; writing-original draft preparation, M.C.C.; writing-review and editing, S.V.; supervision, V.C. and S.V. All authors have read and agreed to the published version of the manuscript.

Funding: This research received no external funding.

Conflicts of Interest: The authors declare no conflict of interest.

\section{References}

1. Ensign, P.C. Knowledge Sharing among Scientists: Why Reputation Matters for RED in Multinational Firms; Palgrave Macmillan: New York, NY, USA, 2008.

2. Gokhale, A.A. Collaborative learning enhances critical thinking. J. Technol. Educ. 1995, 7, 22-30. [CrossRef]

3. Alonso, F.; Manrique, D.; Martinez, L.; Vines, J.M. Study of the influence of social relationships among students on knowledge building using a moderately constructivist learning model. J. Educ. Comput. Res. 2015, 51, 417-439. [CrossRef]

4. Levy, M.; Hadar, I.; Te'eni, D.; Unkelos-Shpigel, N.; Sherman, S.; Harel, N. Social networking in an academic conference context: Insights from a case study. Inf. Technol. People 2016, 29, 51-68. [CrossRef]

5. Yan, W.; Zhang, Y. Research universities on the ResearchGate social networking site: An examination of institutional differences, research activity level, and social networks formed. J. Informetr. 2018, 12, 385-400. [CrossRef]

6. Koranteng, F.N.; Wiafe, I. Factors that promote knowledge sharing on academic social networking sites: An empirical study. Educ. Inf. Technol. 2019, 24, 1211-1236. [CrossRef]

7. Tsovaltzi, D.; Greenhow, C.; Asterhan, C. When friends argue: Learning from and through social network site discussions. Comput. Hum. Behav. 2015, 53, 567-569. [CrossRef]

8. Ortega, J.L. Social Network Sites for Scientists: A Quantitative Survey; Chandos Publishing: Oxford, UK, 2016.

9. Lytras, M.D.; Visvizi, A.; Daniela, L.; Sarirete, A.; Ordonez De Pablos, P. Social networks research for sustainable smart education. Sustainability 2018, 10, 2974. [CrossRef]

10. Zhao, J.; Zhu, C.; Peng, Z.; Xu, X.; Liu, Y. User willingness toward knowledge sharing in social networks. Sustainability 2018, 10, 4680. [CrossRef] 
11. Corvello, V.; Genovese, A.; Verteramo, S. Knowledge sharing among users of scientific social networking platforms. In DSS 2.0-Supporting Decision Making with New Technologies; Phillips-Wren, G., Carlsson, S., Respício, A., Brézillon, P., Eds.; IOS Press: Amsterdam, The Netherlands, 2014; pp. 369-380. Available online: http://ebooks.iospress.nl/volumearticle/36223 (accessed on 10 November 2020).

12. Elsayed, A.M. The use of academic social networks among Arab researchers: A Survey. Soc. Sci. Comput. Rev. 2016, 34, 378-391. [CrossRef]

13. ResearchGate. Available online: https://www.researchgate.net/about (accessed on 23 March 2020).

14. Academia.edu. Available online: https://www.academia.edu/ (accessed on 23 March 2020).

15. Mendeley. Available online: https://www.mendeley.com/?interaction_required=true (accessed on 23 March 2020).

16. Jordan, K. Academics' awareness, perceptions and uses of social networking sites: Analysis of a social networking sites survey dataset. SSRN Electron. J. 2014. [CrossRef]

17. Dermentzi, E.; Papagiannidis, S.; Osorio Toro, C.; Yannopoulou, N. Academic engagement: Differences between intention to adopt social networking sites and other online technologies. Comput. Hum. Behav. 2016, 61, 321-332. [CrossRef]

18. Ortega, J.L. Toward a homogenization of academic social sites: A longitudinal study of profiles in Academia.edu, Google Scholar Citations and ResearchGate. Online Inf. Rev. 2017, 41, 812-825. [CrossRef]

19. Mason, S. Adoption and usage of academic social networks: A Japan case study. Scientometrics 2020, 122, 1751-1767. [CrossRef]

20. Manca, S.; Ranieri, M. "Yes for sharing, no for teaching!": Social media in academic practices. Internet High. Educ. 2016, 29, 63-74. [CrossRef]

21. Sababi, M.; Marashi, S.-A.; Pourmajidian, M.; Tabatabaei, S.; Darki, F.; Sadrzadeh, M.R.; Dehghani, M.; Zandieh, A.; Zim, M.K.; Yousefi, M.; et al. How accessibility influences citation counts: The case of citations to the full text articles available from ResearchGate. J. Res. Policy Eval. 2017, 5, 1-12.

22. Jeng, W.; He, D.; Jiang, J. User participation in an academic social networking service: A survey of open group users on mendeley. J. Assoc. Inf. Sci. Technol. 2015, 66, 890-904. [CrossRef]

23. Lee, S.; Bozeman, B. The impact of research collaboration on scientific productivity. Soc. Stud. Sci. 2005, 35, 673-702. [CrossRef]

24. Defazio, D.; Lockett, A.; Wright, M. Funding incentives, collaborative dynamics and scientific productivity: Evidence from the EU framework program. Res. Policy 2009, 38, 293-305. [CrossRef]

25. Duque, R.B.; Ynalvez, M.; Sooryamoorthy, R.; Mbatia, P.; Dzorgbo, D.-B.S.; Shrum, W. Collaboration paradox: Scientific productivity, the internet, and problems of research in developing areas. Soc. Stud. Sci. 2005, 35, 755-785. [CrossRef]

26. Corley, E.A.; Bozeman, B.; Zhang, X.; Tsai, C.C. The expanded scientific and technical human capital model: The addition of a cultural dimension. J. Technol. Transf. 2019, 44, 681-699. [CrossRef]

27. Pang, S.; Bao, P.; Hao, W.; Kim, J.; Gu, W. Knowledge sharing platforms: An empirical study of the factors affecting continued use intention. Sustainability 2020, 12, 2341. [CrossRef]

28. Kpolovie, P.J. Multiple prediction of research productivity: H-index. Adv. Soc. Sci. Res. J. 2018, 5, 110-135.

29. Gómez-Solórzano, M.; Tortoriello, M.; Soda, G. Instrumental and affective ties within the laboratory: The impact of informal cliques on innovative productivity. Strateg. Manag. J. 2019, 40, 1593-1609. [CrossRef]

30. Auranen, O.; Nieminen, M. University research funding and publication performance-An international comparison. Res. Policy 2010, 39, 822-834. [CrossRef]

31. Fullwood, R.; Rowley, J. An investigation of factors affecting knowledge sharing amongst UK academics. J. Knowl. Manag. 2017, 21, 1254-1271. [CrossRef]

32. Rahman, M.; Osmangani, A.; Daud, N.; AbdelFattah, F. Knowledge sharing behaviors among non academic staff of higher learning institutions: Attitude, subjective norms and behavioral intention embedded model. Libr. Rev. 2016, 65, 65-83. [CrossRef]

33. Killingsworth, B.; Xue, Y.; Liu, Y. Factors influencing knowledge sharing among global virtual teams. Team Perform. Manag. 2016, 22, 284-300. [CrossRef]

34. Hao, Q.; Yang, W.; Shi, Y. Characterizing the relationship between conscientiousness and knowledge sharing behavior in virtual teams: An interactionist approach. Comput. Hum. Behav. 2019, 91, 42-51. [CrossRef]

35. Yan, W.; Zhang, Y. User behaviors and network characteristics of US research universities on an academic social networking site. High. Educ. 2019, 78, 221-240. [CrossRef] 
36. D'Alessandro, S.; Miles, M.; Martínez-López, F.J.; Anaya-Sánchez, R.; Esteban-Millat, I.; Torrez-Meruvia, H. Promote or perish? A brief note on academic social networking sites and academic reputation. J. Mark. Manag. 2020, 36, 405-411. [CrossRef]

37. Ostermaier-Grabow, A.; Linek, S.B. Communication and self-presentation behavior on academic social networking sites: An exploratory case study on profiles and discussion threads on ResearchGate. J. Assoc. Inf. Sci. Technol. 2019, 70, 1153-1164. [CrossRef]

38. Nández, G.; Borrego, A. Use of social networks for academic purposes: A case study. Electron. Libr. 2013, 31, 781-791. [CrossRef]

39. Lee, Y.-H.; Hsiao, C.; Weng, J.; Chen, Y.-H. The impacts of relational capital on self-disclosure in virtual communities: A cross-level analysis of key moderators. Inf. Technol. People 2020, (in press). [CrossRef]

40. Deng, Y.; Xie, Y.; Li, Y.; Yang, M.; Du, N.; Fan, W.; Lei, K.; Shen, Y. Multitask learning with multi-view attention for answer selection and knowledge base question answering. In Proceedings of the Thirty-Third AAAI Conference on Artificial Intelligence (AAAI 2019), The Thirty-First Innovative Applications of Artificial Intelligence Conference (IAAI 2019), The Ninth AAAI Symposium on Educational Advances in Artificial Intelligence, EAAI 2019, Honolulu, HI, USA, 27 January-1 February 2019; pp. 6318-6325.

41. Li, L.; Zhang, C.; He, D.; Du, J.T. Researchers' judgment criteria of high-quality answers on academic social Q\&A platforms. Online Inf. Rev. 2020, 44, 603-623.

42. Waheed, M.; Klobas, J.E.; Ain, N. Unveiling knowledge quality, researcher satisfaction, learning, and loyalty: A model of academic social media success. Inf. Technol. People 2020, (in press). [CrossRef]

43. Jamali, H.R. Copyright compliance and infringement in ResearchGate full-text journal articles. Scientometrics 2017, 112, 241-254. [CrossRef]

44. Almousa, O.S. Users' distribution and behavior in academic social networking sites. Int. J. E Collab. 2018, 14, 49-65. [CrossRef]

45. Deng, S.; Jingjing, T.; Yangqing, L.; Yong, L. Motivating scholars' responses in academic social networking sites: An empirical study on ResearchGate Q\&A behavior. Inf. Process. Manag. 2019, 56, 6.

46. Jordan, K. From social networks to publishing platforms: A review of the history and scholarship of academic social network sites. Front. Digit. Humanit. 2019, 6, 5. [CrossRef]

47. Williams, A.E. Exploring the utility of Academia.edu: A SWOT analysis. Inf. Learn. Sci. 2018, 119, $662-666$. [CrossRef]

48. Lee, J.; Oh, S.; Dong, H.; Wang, F.; Burnett, G. Motivations for self-archiving on an academic social networking site: A study on ResearchGate. J. Assoc. Inf. Sci. Technol. 2019, 70, 563-574. [CrossRef]

49. Yu, M.-C.; Jim, W.Y.-C.; Alhalabi, W.; Kao, H.-Y.; Wu, W.-H. ResearchGate: An effective altmetric indicator for active researchers? Comput. Hum. Behav. 2016, 55, 1001-1006. [CrossRef]

50. Oh, J.S.; Jeng, W. Groups in academic social networking services: An exploration of their potential as a platform for multi-disciplinary collaboration. In Proceedings of the IEEE Third International Conference on Privacy, Security, Risk and Trust and 2011 IEEE Third International Conference on Social Computing, Boston, MA, USA, 9-11 October 2011; pp. 545-548.

51. Alheyasat, O. Examination expertise sharing in academic social networks using graphs: The case of ResearchGate. Contemp. Eng. Sci. 2015, 8, 137-151. [CrossRef]

52. Manca, S. Researchgate and academia.edu as networked socio-technical systems for scholarly communication: A literature review. Res. Learn. Technol. 2018, 26, 1-16. [CrossRef]

53. Yan, W.; Zhang, Y.; Bromfield, W. Analyzing the follower-followee ratio to determine user characteristics and institutional participation differences among research universities on ResearchGate. Scientometrics 2018, 115, 299-316. [CrossRef]

54. Djonov, E.; Van Leeuwen, T. Social media as semiotic technology and social practice: The case of ResearchGate's design and its potential to transform social practice. Soc. Semiot. 2018, 28, 641-664. [CrossRef]

55. Chen, C.-J.; Hung, S.W. To give or to receive? Factors influencing members' knowledge sharing and community promotion in professional virtual communities. Inf. Manag. 2010, 47, 226-236. [CrossRef]

56. Jin, J.; Li, Y.; Zhong, X.; Zhai, L. Why users contribute knowledge to online communities: An empirical study of an online social Q\&A community. Inf. Manag. 2015, 52, 840-849.

57. Jiang, G.; Shang, J.; Liu, W.; Feng, X.; Lei, J. Modeling the dynamics of online review life cycle: Role of social and economic moderations. Eur. J. Oper. Res. 2020, 285, 360-379. [CrossRef] 
58. Hara, N.; Foon Hew, K. Knowledge-sharing in an online community of health-care professionals. Inf. Technol. People 2007, 20, 235-261. [CrossRef]

59. Lepori, B.; Thelwall, M.; Hoorani, B.H. Which US and European higher education institutions are visible in ResearchGate and what affects their RG score? J. Informetr. 2018, 12, 806-818. [CrossRef]

60. Chang, H.H.; Chuang, S.S. Social capital and individual motivations on knowledge sharing: Participant involvement as a moderator. Inf. Manag. 2011, 48, 9-18. [CrossRef]

61. Levin, D.Z.; Whitener, E.M.; Cross, R. Perceived trustworthiness of knowledge sources: The moderating impact of relationship length. J. Appl. Psychol. 2006, 91, 1163-1171. [CrossRef] [PubMed]

62. Chiu, C.M.; Hsu, M.H.; Wang, E.T.G. Understanding knowledge sharing in virtual communities: An integration of social capital and social cognitive theories. Decis. Support Syst. 2006, 42, 1872-1888. [CrossRef]

63. Han, H.; Hsu, L.; Sheu, C. Application of the theory of planned behavior to green hotel choice: Testing the effect of environmental friendly activities. Tour. Manag. 2010, 31, 325-334. [CrossRef]

64. Cohen, J.B.; Fishbein, M.; Ahtolam, O.T. The nature and uses of expectancy-value models in consumer attitude research. J. Mark. Res. 1972, 9, 456-460. [CrossRef]

65. Churchill, G.A. A paradigm for developing better measures of marketing constructs. J. Mark. Res. 1979, 16, 64-73. [CrossRef]

66. Nunnally, J.C. Psychometric Theory; McGraw-Hill: New York, NY, USA, 1978.

67. Podsakoff, P.M.; MacKenzie, S.B.; Lee, J.-Y.; Podsakoff, N.P. Common method biases in behavioral research: A critical review of the literature and recommended remedies. J. Appl. Psychol. 2003, 88, 879-903. [CrossRef]

68. Streiner, D.L. Finding our way: An introduction to path analysis. Can. J. Psychiatry 2005, 50, 115-122. [CrossRef]

69. Streiner, D.L. Building a better model: An introduction to structural equation modelling. Can. J. Psychiatry 2006, 51, 317-324. [CrossRef]

70. Kline, R.B. Principles and Practice of Structural Equation Modeling; Guilford Press: New York, NY, USA, 1998.

71. Hair, J.F.; Tatham, R.L.; Anderson, R.E.; Black, W. Multivariate Data Analysis with Readings; Prentice-Hall: Upper Saddle River, NJ, USA, 1998.

72. Anderson, J.C.; Gerbing, D.W. Structural equation modeling in practice: A review and recommended two-step approach. Psychol. Bull. 1988, 103, 411-423. [CrossRef]

73. Hair, J.F.; Black, W.C.; Babin, B.J.; Anderson, R.E.; Tatham, R.L. Multivariant Data Analysis; Pearson International Edition: London, UK, 2006.

74. Ford, J.K.; MacCallum, R.C.; Tait, M. The applications of exploratory factor analysis in applied psychology: A critical review and analysis. Pers. Psychol. 1986, 39, 291-314. [CrossRef]

75. Cronbach, L.J. Coefficient alpha and the internal structure of tests. Psychometrika 1951, 16, 297-334. [CrossRef]

76. Jöreskog, K.G.; Sörbom, D. LISREL 8: Structural Equation Modeling with the SIMPLIS Command Language; Scientific Software International: Skokie, IL, USA, 1993.

77. Kim, K.S. Structural Equation Modeling Analysis; Hannarae: Seoul, Korea, 2008.

78. Reisinger, Y.; Turner, L. Structural equation modeling with lisrel: Application in tourism. Tour. Manag. 1999, 20,71-88. [CrossRef]

79. De Vellis, R.F. Scale Development: Theory and Applications; SAGE Publications: Thousand Oaks, CA, USA, 1991.

80. Huh, M.H. Statistics Analysis; Bobmunsa: Seoul, Korea, 2001.

81. Horn, J.L. A rationale and test for the number of factors in factor analysis. Psychometrika 1965, 30, $179-185$. [CrossRef]

82. Keeling, K.B. A regression equation for determining the dimensionality of data. Multivar. Behav. Res. 2000, 35, 457-468. [CrossRef]

83. Lautenschlager, G.J.; Lance, C.E.; Flaherty, V.L. Parallel analysis criteria: Revised equations for estimating the latent roots of random data correlation matrices. Educ. Psychol. Meas. 1989, 49, 339-345. [CrossRef]

84. Kim, D.U. AMOS A to Z: Structural Equation Modeling for Writing Papers; Hakhyunsa: Paju, Korea, 2008.

85. Bagozzi, R.P.; Yi, Y. On the evaluation of structural equation models. J. Acad. Mark. Sci. 1988, 16, 74-94. [CrossRef]

86. Kim, K. Analysis of structural equation model for the student pleasure travel market: Motivation, involvement, satisfaction, and destination loyalty. J. Travel Tour. Mark. 2008, 24, 297-313. [CrossRef]

87. Fornell, C.; Larcker, D.F. Evaluating structural equation models with unobservable variables and measurement error. J. Mark. Res. 1981, 18, 39-50. [CrossRef] 
88. Corvello, V.; Felicetti, A.M. Factors affecting the utilization of knowledge acquired by researchers from scientific social networks: An empirical analysis. Knowl. Manag. 2014, 13, 26. [CrossRef]

89. Hafeez, K.; Alghatas, F.M.; Foroudi, P.; Nguyen, B.; Gupta, S. Knowledge sharing by entrepreneurs in a virtual community of practice VCoP. Inf. Technol. People 2019, 32, 405-429. [CrossRef]

90. Evans, M.; Wensley, A.; Frissen, I. The mediating effects of trustworthiness on social-cognitive factors and knowledge sharing in a large professional service firm. Electron. J. Knowl. Manag. 2015, 13, 240-254.

Publisher's Note: MDPI stays neutral with regard to jurisdictional claims in published maps and institutional affiliations.

(C) 2020 by the authors. Licensee MDPI, Basel, Switzerland. This article is an open access article distributed under the terms and conditions of the Creative Commons Attribution (CC BY) license (http://creativecommons.org/licenses/by/4.0/). 